\title{
Ventricular tachycardia induced by clonidine withdrawal
}

\author{
SUSUMU NAKAGAWA, YOSHITAKA YAMAMOTO, YASUSHI KOIWAYA \\ From the First Department of Internal Medicine, Miyazaki Medical College, Kiyotake, Miyazaki, fapan
}

SUMmARY Ventricular tachycardia developed after the abrupt withdrawal of clonidine in a patient with atrial septal defect of the ostium secundum type, renal insufficiency, and hypertension. Ventricular tachycardia was completely suppressed by intravenous phentolamine, which contrasted with the limited effectiveness of intravenous lignocaine and procainamide. Sublingual glyceryl trinitrate or inhaled amyl nitrate reduced the blood pressure to a level similar to that after phentolamine but had no effect on the ventricular tachycardia. Ventricular tachycardia was probably produced by humoral or neural stimulation, or both, of upregulated myocardial alpha adrenoceptors.

It is known that the abrupt withdrawal of clonidine hydrochloride (clonidine) is often associated with a syndrome characterised by excessive efferent sympathetic activity producing raised serum catecholamine concentrations and clinical manifestations similar to those in pheochromocytoma. ${ }^{1-4}$ Although frequent atrial and ventricular extrasystoles have been reported, ${ }^{1}$ serious ventricular arrhythmias are rare in the clonidine withdrawal syndrome. To our knowledge, only one case of ventricular fibrillation has been reported 12 hours after the withdrawal of clonidine during aortocoronary bypass surgery. ${ }^{2}$

We report a patient with atrial septal defect of the ostium secundum type, chronic renal failure, and hypertension, who experienced paroxysmal ventricular tachycardia two days after stopping oral clonidine.

\section{Case report}

A 60 year old woman with atrial septal defect had an eight year history of hypertension and intermittent pretibial oedema. Her blood pressure was 165/ $105 \mathrm{~mm} \mathrm{Hg}$, and she was treated with $0.45 \mathrm{mg}$ clonidine daily. One month later her blood urea nitrogen concentration was $18.9 \mathrm{mmol} / 1(53.0 \mathrm{mg} /$ $100 \mathrm{ml}$ ) and serum creatinine concentration $203 \mathrm{mmol} / \mathrm{l}(2.3 \mathrm{~g} / 100 \mathrm{ml})$. She was admitted to our clinic for further evaluation of progressive oedema

Requests for reprints to Dr Susumu Nakagawa, First Department of Internal Medicine, Miyazaki Medical College, 5200 Kihara, Kiyotake, Miyazaki 889-16, Japan. eight months later. Two days before admission she had stopped taking clonidine (Fig. 1).

On admission, her height was $148 \mathrm{~cm}$, weight $46 \mathrm{~kg}$, body temperature $36.3^{\circ} \mathrm{C}$, and blood pressure $130 / 80 \mathrm{~mm} \mathrm{Hg}$. No cyanosis was noticed. The jugular veins were slightly distended and minimal pretibial pitting oedema was present. The pulse was irregular at a rate of 120 beats $/ \mathrm{min}$, the respiratory rate was $18 / \mathrm{min}$, and a grade $3 / 6$ early systolic murmur was heard most clearly in the third intercostal space at the left sternal border. The two components of the second heart sound were widely separated, which was confirmed by a phonocardiogram. The resting electrocardiogram showed normal sinus rhythm with paroxysmal ventricular tachycardia (Fig. 2a) and inverted $T$ waves in the precordial leads.

A chest radiograph showed increased pulmonary markings, a pronounced convexity of the cardiac shadow to the right of the sternum, a normal sized aortic knuckle, and a prominent pulmonary knuckle. $M$ mode and cross sectional echocardiograms showed an enlarged right ventricle, paradoxical motion of the interventricular septum, a narrow left ventricular outflow tract, and a high $D$ point of the mitral valve.

Serum sodium concentration was $148 \mathrm{mmol} / \mathrm{l}$, potassium $4.9 \mathrm{mmol} / \mathrm{l}$, chloride $111 \mathrm{mmol} / \mathrm{l}$, bicarbonate $16.2 \mathrm{mmol} / \mathrm{l}$, calcium $77 \mathrm{mg} / \mathrm{l}$, phosphorus $62 \mathrm{mg} / \mathrm{l}$, lactate dehydrogenase activity $564 \mathrm{IU} / \mathrm{l}$, serum aspartate aminotransferase activity $46 \mathrm{IU} / \mathrm{l}$, serum alanine aminotransferase activity $48 \mathrm{IU} / \mathrm{l}$, and creatine phosphokinase activity $131 \mathrm{IU} / \mathrm{l}$. Packed cell volume was $36.8 \%$, haemoglobin $11.8 \mathrm{~g} / \mathrm{dl}$, red blood cell count $4.13 \times 10^{12} / 1$, and white blood cell 


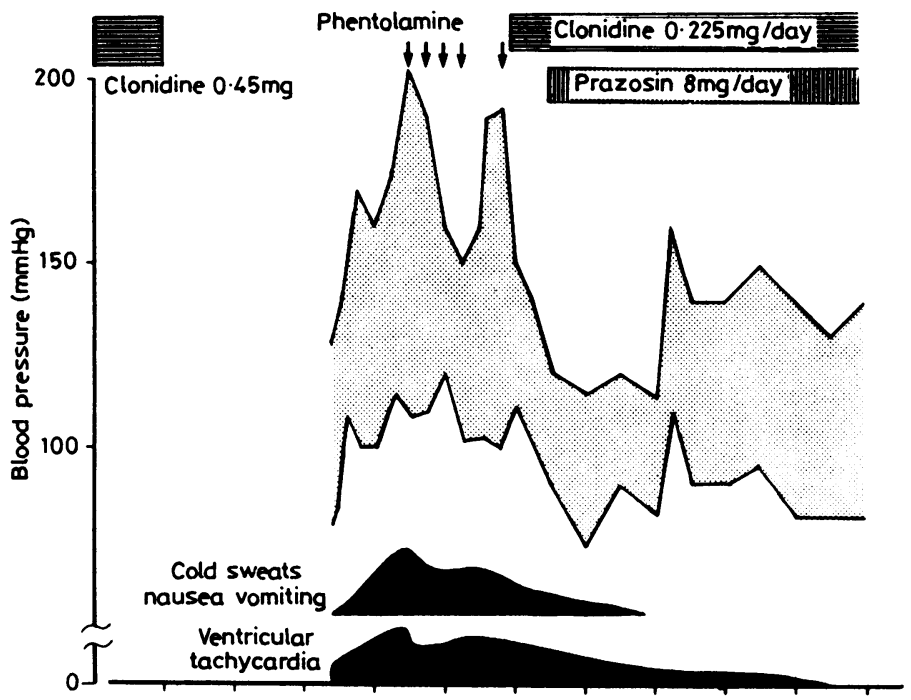

Fig. 1 Relation between blood pressure, blood urea nitrogen concentration, serum creatinine concentration, serum potassium concentration, and adrenaline and noradrenaline concentrations and administration of phentolamine, prazosin, and clonidine.

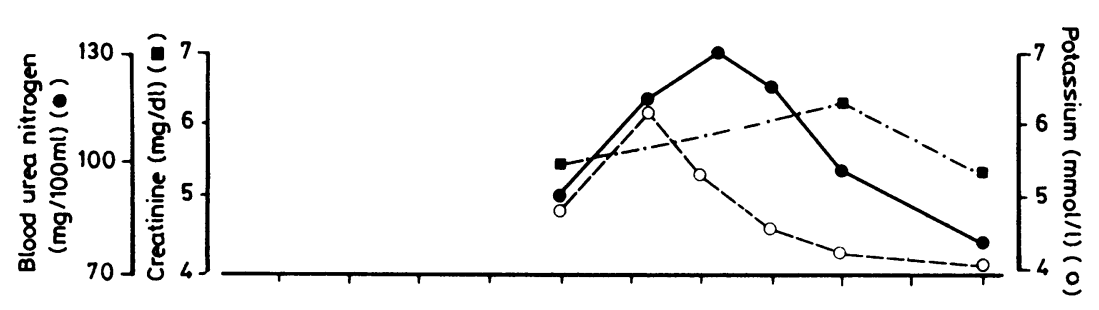

Conversion: SI to traditional units-urea nitrogen: $1 \mathrm{mmol} / \mathrm{l} \approx 2.8$ $\mathrm{mg} / \mathrm{dl}$; creatinine: 1 molll $\approx$ $0.01 \mathrm{~g} / \mathrm{dl}$; adrenaline: $1 \mathrm{ng} / 100 \mathrm{ml} \approx$ 0.054 nmolll; noradrenaline $1 \mathrm{ng} / 100 \mathrm{ml} \approx 0.059 \mathrm{nmol} / \mathrm{l}$.

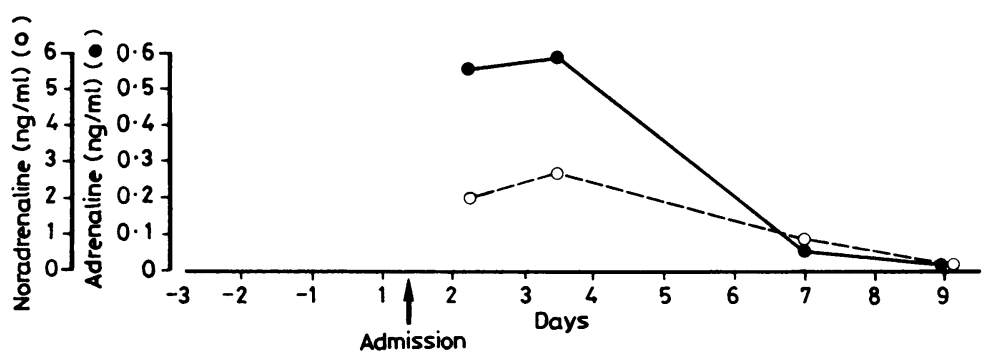

count $6.9 \times 10^{9} / 1$. Blood urea nitrogen concentration was $32 \mathrm{mmol} / \mathrm{l} \quad(90.2 \mathrm{mg} / 100 \mathrm{ml})$, creatinine $486 \mu \mathrm{mol} / 1(5.5 \mathrm{mg} / 100 \mathrm{ml})$ and calculated creatinine clearance $9.24 \mathrm{ml} / \mathrm{min}$. Urine analysis showed $400 \mathrm{mg} / \mathrm{l}$ of protein.

Blood pressure rose gradually to $220 / 120 \mathrm{~mm} \mathrm{Hg}$ by midday of the second hospital day (Fig. 1). Nausea, vomiting, and cold sweats developed concomitantly, and the intervals between episodes of paroxysmal ventricular tachycardia were shorter (Fig. $2 b)$. Serum adrenaline and noradrenaline concentrations appreciably increased $(3.2 \mathrm{nmol} / \mathrm{l}(0.59 \mathrm{ng} / \mathrm{ml})$ and $15.6 \mathrm{nmol} / \mathrm{l}(2.64 \mathrm{ng} / \mathrm{ml})$ respectively) (Fig. $2 \mathrm{c}$ ), and a diagnosis of clonidine withdrawal syndrome was made.
Intravenous lignocaine $100 \mathrm{mg}$ and procainamide $200 \mathrm{mg}$ failed to suppress the ventricular tachycardia completely. Nevertheless, an intravenous injection of $10 \mathrm{mg}$ phentolamine completely suppressed ventricular tachycardia within two minutes with a decrease in blood pressure and pronounced symptomatic improvement (Figs. 2b and c). Repeated doses of phentolamine achieved similar results, while serum catecholamine concentrations were unchanged by phentolamine after 30 minutes (Fig. 2c). To examine the effects of the fall in blood pressure and afterload reduction of arrhythmias, we gave glyceryl trinitrate or amyl nitrate. Sublingual glyceryl trinitrate $0.3 \mathrm{mg}$ decreased arterial pressure from $196 / 106 \mathrm{~mm} \mathrm{Hg}$ to $170 / 102 \mathrm{~mm} \mathrm{Hg}$, and the inhalation of amyl nitrate 


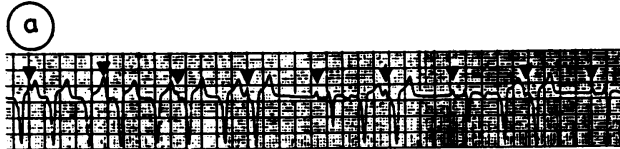

(b)

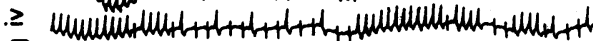

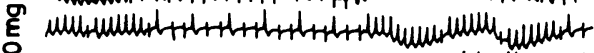
으

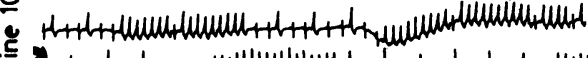

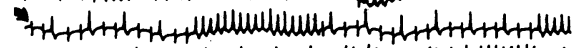

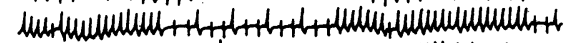

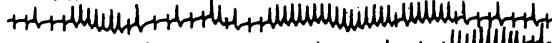

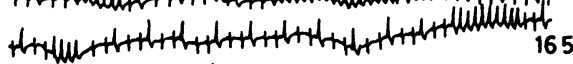

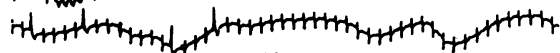

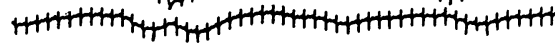

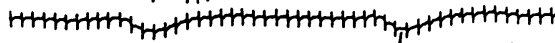

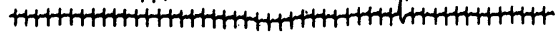

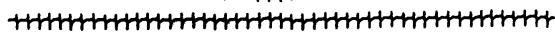

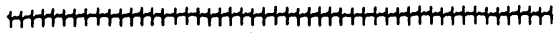

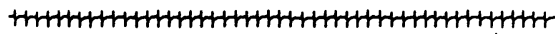

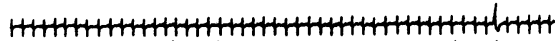

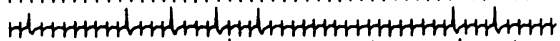

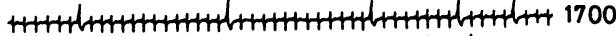

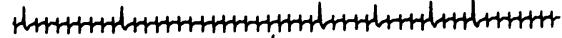

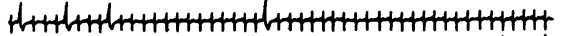

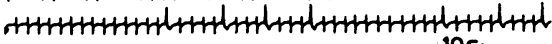
105

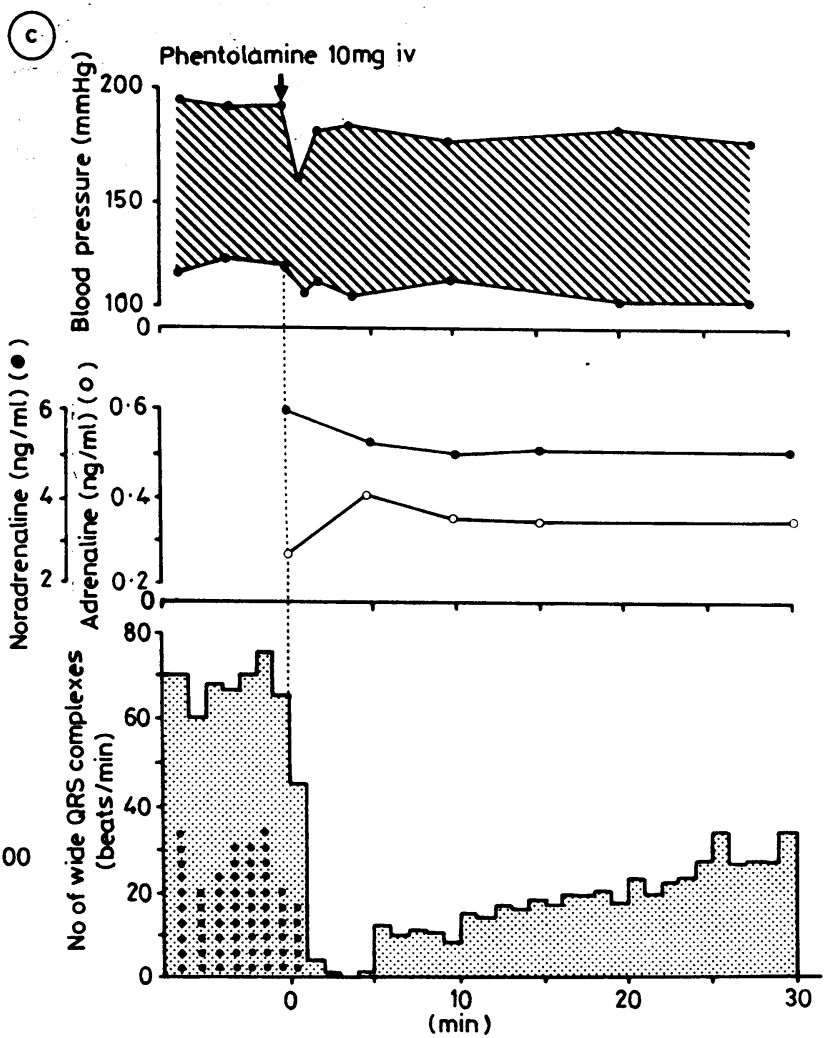

Fig. 2 (a) Electrocardiogram (lead V2) ( $\nabla$ denotes $P$ ware), (b) continuous electrocardiogram (lead CM5) before and after intravenous phentolamine, and (c) chronological changes in blood pressure, senom adrenaline, and noradrenaline concentrations, and frequency of wide $Q R S$ complexes ( denotes momber of episodes of ventricular tachycardia ( $>3$ consecutive wide $Q R S$ complexes)) before and after intravenous phentolamine. Repetitive nuns of ventricular tachycardia were recorded and were suppressed completely two minutes after intravenous phentolamine.

Conversion: SI to traditional units-adrenaline: $1 \mathrm{ng} / 100 \mathrm{ml} \approx 0.054$ molll; noradrenaline $1 \mathrm{ng} / 100 \mathrm{ml} \approx 0.059 \mathrm{nmol} / \mathrm{l}$.

from $184 / 116 \mathrm{~mm} \mathrm{Hg}$ to $160 / 106 \mathrm{~mm} \mathrm{Hg}$. Neither agent, however, affected the occurrence or frequency of episodes of ventricular tachycardia.

Renal function progressively deteriorated after admission, with the blood urea nitrogen concentration rising to $46.4 \mathrm{mmol} / 1(130 \mathrm{mg} / 100 \mathrm{ml})$ and potassium concentration to $6.2 \mathrm{mmol} / /$. We began treatment with $0.225 \mathrm{mg}$ clonidine and $8 \mathrm{mg}$ prazosin daily on the third and fourth hospital day respectively, which lowered the blood pressure to $120 / 90 \mathrm{~mm} \mathrm{Hg}$ within 12 hours and symptoms subsided within 48 hours. The number of episodes of ventricular tachycardia decreased gradually, and the arrhythmia did not recur after the ninth hospital day (Fig. 1). The concentrations of blood urea nitrogen, creatinine, and serum potassium fell to the values before admission on the ninth hospital day.

The clinical course was uneventful with treatment until two months later, when she developed severe headaches with neck rigidity. She collapsed suddenly and cardiopulmonary resuscitation was unsuccessful. Necropsy showed a massive subarachnoid haemorrhage secondary to rupture of an aneurysm of the left anterior communicating artery, a large ostium secundum defect, and chronic glomerulonephritis. No evidence of pheochromocytoma or significant coronary atherosclerosis was found.

\section{Discussion}

In our patient, in whom paroxysmal ventricular tachycardia occurred after abruptly stopping clonidine, the arrhythmia was probably a manifestation of clonidine withdrawal since it occurred in conjunction with other clinical evidence of this syndrome including raised serum catecholamine concentrations. Furthermore, intravenous phentolamine or oral clonidine (the usual therapeutic drugs for the 
clonidine withdrawal syndrome) was more effective in controlling ventricular tachycardia than other regularly used antiarrhythmic agents.

The mechanism of ventricular tachycardia associated with clonidine withdrawal is unknown. Nevertheless, there are several possible theories. Firstly, high blood pressure is known to aggravate catecholamine induced arrhythmias. ${ }^{5}$ The effectiveness of phentolamine in suppressing ventricular tachycardia in this patient might have been due to the accompanying fall in blood pressure. This possibility is, however, unlikely since sublingual glyceryl trinitrate or inhaled amyl nitrate, sufficient to reduce blood pressure to the level similar to that after phentolamine, had no effect on ventricular tachycardia.

Secondly, ventricular tachycardia might have been caused by direct stimulation of the myocardial adrenoceptors by circulating catecholamines or cardiac sympathetic nerves. The notable effect of phentolamine on ventricular tachycardia in contrast to the limited effectiveness of the usual antiarrhythmic drugs strongly suggests that alpha adrenergic mechanisms were involved in the genesis of ventricular tachycardia. A beta blocker was not given because of possible worsening of the withdrawal syndrome..$^{1-4}$

Recently, the presence of myocardial alpha receptors has been reported experimentally, ${ }^{6}$ and their role in the genesis of some specific cardiac arrhythmias has been clarified. Picrotoxin, a central nervous system stimulant, produces demonstrable ventricular tachyarrhythmias in animals, ${ }^{7}$ and these tachyarrhythmias can be suppressed by phentolamine but not by propranolol. These arrhythmias are thought to be caused by stimulation of myocardial alpha receptors by cardiac sympathetic nerves or by circulating catecholamines released from the adrenal gland or both. Cor and Crafford and Sheridan et al found alpha blockade to be effective in suppressing ventricular tachyarrhythmias induced by coronary artery reperfusion in cats. ${ }^{68}$ They found an increased number and affinity of myocardial alpha receptors in this experimental model. ${ }^{6}$

It is likely that sympathetic hyperactivity associated with clonidine withdrawal involves predominantly alpha adrenergic mechanisms since alpha blockers usually relieve the clinical symptoms of clonidine withdrawal, while beta blockers occasionally make them worse. ${ }^{1-4}$ Why alpha adrenergic hyperactivity predominates in this syndrome is not known, but it is likely that upregulation of alpha adrenergic receptors occurs after the abrupt withdrawal of clonidine. ${ }^{4}$

Clonidine reduces the release of noradrenaline into the synapse, acting as a presynaptic alpha receptor agonist, and, furthermore, behaves as an alpha adrenergic antagonist postsynaptically. Thus sustained treatment with clonidine results in a loss of noradrenaline-receptor interaction at the synapse with an increase of alpha receptor concentration postsynaptically. ${ }^{910}$ The abrupt withdrawal of clonidine results in increased efferent sympathetic outflow with enhanced release of catecholamines from the adrenal gland and sympathetic nerve endings. ${ }^{4}$ Increased activation of synaptic alpha receptors, which had increased in number or affinity or both, by the enhanced adrenergic stimulus results in a withdrawal syndrome. An increase in the alpha receptors of the ventricular myocardium after long term treatment with clonidine has been reported. ${ }^{10}$ In the present case increased sympathetic outflow to the heart and raised serum catecholamine concentrations would have stimulated the increased cardiac alpha receptors and thus induced ventricular tachycardia. The antiarrhythmic action of phentolamine would have been mediated by the inhibition of cardiac alpha receptors.

The antiarrhythmic effect of phentolamine could have been exerted in the central nervous system, but such a mechanism was probably not predominant since phentolamine penetrates the blood-brain barrier poorly, while a bolus injection of $10 \mathrm{mg}$ phentolamine was sufficient to suppress ventricular tachycardia within two minutes. It is not likely that the minor quinidine like antiarrhythmic action of phentolamine ${ }^{11}$ played an important role in our case, since other regularly used antiarrhythmic agents with quinidine like action were not as effective as phentolamine.

Our case was complicated by chronic glomerulonephritis with renal insufficiency, long standing hypertension, and atrial septal defect, which might have predisposed to ventricular tachycardia. Renal insufficiency would have resulted in a high blood concentration of clonidine and led to the withdrawal syndrome since clonidine is excreted mainly by the kidney. ${ }^{3}$

\section{References}

1 Goldberg AD, Wilkinson PR, Raftery EB. The overshoot phenomenon on withdrawal of clonidine therapy. Postgrad Med F 1976; 52 (suppl 7): 128-34.

2 O'Connor DE. Accelerated acute clonidine withdrawal syndrome during coronary bypass surgery. A case report. Br F Anaesth 1981; 53: 431-3.

3 Houston MC. Clonidine hydrochloride: review of pharmacologic and clinical aspects. Prog Cardiovasc Dis 1981; 23: 337-50.

4 Whitsett TL. Abrupt cessation of treatment with centrally acting antihypertensive agents; a review. Chest 1983; 83 (suppl): 400-2.

5 Dresel P, Sutter MC. Factors modifying cyclopropaneepinephrine cardiac arrhythmias. Circ Res 1961; 9: 
$1284-90$.

6 Corr PB, Crafford WA Jr. Enhanced alpha-adrenergic responsiveness in ischemic myocardium: role of alphaadrenergic blockade. Am Heart f 1981; 102: 605-12.

7 DiMicco JA, Prestel T, Pearle DL, Gillis RA. Mechanism of cardiovascular changes produced in cats by activation of the central nervous system with picrotoxin. Circ Res 1977; 41: 446-51.

8 Sheridan DJ, Penkoske PA, Sobel BE, Corr PB. Alphaadrenergic contributions to dysrhythmia during myocardial ischemia and reperfusion in cats. F Clin Invest 1980;
65: 161-71.

9 Isaac L. Clonidine in the central nervous system: site and mechanism of hypotensive action. $\mathcal{f}$ Cardiovasc Pharmacol 1980; 2 (suppl 1): s5-19.

10 Yamada S, Yamamura HI, Roeske WR. An increase in cardiac alpha ${ }_{1}$-adrenoreceptors following chronic clonidine treatment. Naunyn Schmiedebergs Arch Pharmacol 1982; 320: 115-8.

11 Gould L, Reddy CVR, Weinstein T, Gomprecht RF. Antiarrhythmic prophylaxis with phentolamine in acute myocardial infarction. $\mathcal{F}$ Clin Pharmacol 1975; 15: 191-7. 